UDC 624.137 .2

Anatolii P. Sirenko, PhD, Docent, Docent of Department of dynamics and strength machines and strength of materials of the Institute of Mechanical Engineering

ORCID ID: 0000-0002-4951-1165 e-mail: sirenkoap@gmail.com

National Technical University of Ukraine «Igor Sikorsky Kyiv Polytechnic Institute», Kyiv, Ukraine

\title{
TO THE ANALYSIS OF METHODS OF CALCULATION OF STABILITY OF USE AND THEIR CLASSIFICATION
}

\begin{abstract}
The problem of assessing the stability of slopes is quite relevant in the development of mineral deposits in an open way, in hydraulic engineering and transport, industrial and civil engineering, as well as in other areas of human activity. Attempts to obtain the correct method of calculation led to the emergence of a large number of methods, methods of calculation and calculation schemes: their diversity is explained by the number of assumptions used by researchers to justify the calculation scheme and stability conditions. The task of determining the parameters of a steady slope or bearing capacity of the base in most cases is statically uncertain. Therefore, for the determination of unknown reactions, the authors put forward additional conditions (assumptions). The variety of existing methods for calculating the stability of slopes caused the need to classify them by one or another feature. Based on a detailed analysis of work in this area, four groups of basic assumptions put forward by researchers for substantiation of the calculation scheme for calculating the stability of slopes, obtaining stability conditions (equilibrium) of the shift prisms, the selection of the shape and position of the weakest surface of slip in the slopes were identified. These are assumptions such as: about the condition of the boundary stress state at each point of the bias prism (the method of the boundary stress state); about the distribution of normal reactions along the surface of the slip (methods of a monolithic compartment of collapse, that is, when considering the balance of the prism of the shear completely); the ratio of tangential and normal reactions at the lateral sides of the compartments (the reaction is horizontal, inclined or marginal rejected); in relation to the shape and position (geometry) of the potential (weakest) surface of the slide. In conclusion, it was concluded that the method of the boundary stress state is most useful for preventing collapses, then studying the shape of slopes and external loading, at which a possible collapse. The method of boundary equilibrium, in turn, is desirable to use for the analysis of a strained state of landslides.
\end{abstract}

Keywords: slope; marginal equilibrium method; limiting stress state method; resilience

\section{А.П. Сіренко}

Національний технічний університет України «Київський політехнічний інститут імені Ігоря Сікорського», м. Київ, Україна

\section{ДО АНАЛІЗУ МЕТОДІВ РОЗРАХУНКУ СТІЙКОСТІ СХИЛІВ ТА ЇХ КЛАСИФІКАЦЇ̈}

Анотація. Проблема оцінки стійкості схилів є досить актуальною при розробиі родовищ корисних копалин відкритим способом, в гідротехнічному $i$ транспортному, промисловому і ицвільному будівництві, а також в інших 
галузях діяльності людства. Спроби отримання коректного способу розрахунку привели до появи великої кількості способів, прийомів розрахунку $i$ розрахункових схем: їх різноманіття пояснюється кількістю припущень, що використовуються дослідниками для обтрунтування розрахункової схеми, і умовами стійкості. Завдання з визначення параметрів стійкого схилу або несучої здатності основи в більшості випадків є статично невизначеним. Тому для визначення невідомих реакиій авторами висуваються додаткові умови (припущення). Різноманіття існуючих способів розрахунку стійкості схилів викликало необхідність класифікувати їх за тими чи іншими ознаками. На підставі детального аналізу робіт у иій галузі було виокремлено чотири групи основних припущень, висунутих дослідниками для обтрунтування схеми розрахунку стійкості схилів, отримання умов стійкості (рівноваги) призми зсуву, виділення форми $і$ положення найбільш слабкої поверхні ковзання в схилах. Це такі допущення, як: про виконання умови граничного напруженого стану в кожній точиі призми зміщення (метод граничного напруженого стану); про розподіл нормальних реакцій уздовж поверхні ковзання (способи монолітного відсіку обвалення, тобто коли розглядають рівновагу призми зсуву иілком); щодо співвідношення дотичних і нормальних реакиій по бічних гранях відсіків (реакиія горизонтальна, нахилена або гранично відхилена); щзодо форми $i$ положення (геометрії) потенційної (найбільш слабкої) поверхні ковзання. У підсумку зроблено висновок, що метод граничного напруженого стану найбільш корисний для попередження обвалів, тобто вивчення форми схилів і зовнішнього навантаження, при яких можливе обвалення схилів. Метод граничної рівноваги, у свою чергу, бажано застосовувати для аналізу напруженого стану зсувів.

Ключові слова: схил; метод граничної рівноваги; метод граничного напруженого стану; стійкість

\section{Вступ}

Проблема оцінки стійкості схилів є досить актуальною при розробленні родовищ корисних копалин відкритим способом в гідротехнічному, транспортному, промисловому і цивільному будівництві, а також в інших галузях діяльності людини [1-5].

Історично першою роботою 3 питань рівноваги масиву, обмеженого нахиленою площиною (схилом), є робота У.Д. Ренкіна (1857). Перший спосіб розрахунку стійкості схилів, заснований на принципі Кулона, був запропонований в 1920 р. Г. Франсе. До теперішнього часу розроблено понад 100 способів, прийомів і схем розрахунку стійкості схилів. Їх різноманіття пояснюється кількістю припущень, що використовуються дослідниками для обгрунтування розрахункових схем, і умовами стійкості. Річ у тім, що завдання 3 визначення параметрів стійкого схилу або несучої здатності основи в будьякій постановці $є$ статично невизначеним. Тому для визначення невідомих реакцій авторами висуваються додаткові умови (припущення). Наприклад, У.Д. Ренкін передбачав, що в кожній точці призми зсуву виконується умова граничної кулонівської рівноваги. Д. Тейлор приймає симетричний синусоїдальний закон розподілу нормальних реакцій уздовж поверхні ковзання. Більшість інших способів допускають нехтування дією міжблокових реакцій, а поверхню ковзання приймають з умови отримання більш простих формул. Тому таке велике різноманіття способів розрахунку викликало необхідність класифікувати їх за тими чи іншими ознаками. 


\section{Основна частина}

Способи класів А, Б та В в таблиці представлені для однорідних схилів, а клас $\boldsymbol{\Gamma}$ - для анізотропних. Жоден 3 цих способів не $\epsilon$ математично коректним, навіть коли йдеться про ідеально однорідні і ізотропні масиви грунту. 3 іншого боку, очевидно, що теорія розрахунку анізотропних схилів повинна базуватися на теорії ізотропних схилів, тому способи класу $\Gamma$ у подальшому виключимо з аналізу.

Таблиця - Класифікація методів (способів) розрахунку стійкості схилів

\begin{tabular}{|c|c|c|c|c|}
\hline Клас & \begin{tabular}{|c|} 
Загальний \\
принцип \\
визначення \\
параметрів \\
стійкого схилу, \\
що характеризує \\
клас методів
\end{tabular} & $\begin{array}{c}\text { Загальна ознака } \\
\text { для групи способів }\end{array}$ & $\begin{array}{c}\text { Основний спосіб } \\
\text { групи }\end{array}$ & $\begin{array}{c}\text { Розрахункові способи } \\
\text { і схеми, що } \\
\text { використовують } \\
\text { основний метод }\end{array}$ \\
\hline 1 & 2 & 3 & 4 & 5 \\
\hline \multirow[t]{2}{*}{$\mathbf{A}$} & $\begin{array}{l}\text { Побудова контуру } \\
\text { схилу, у всіх } \\
\text { точках якого } \\
\text { задовольняється } \\
\text { умова граничного } \\
\text { ненапруженого } \\
\text { стану }\end{array}$ & \begin{tabular}{|l|} 
Чисельний спосіб \\
інтегрування \\
диференціальних \\
рівнянь \\
напруженого стану
\end{tabular} & $\begin{array}{l}\text { Спосіб } \\
\text { В.В. Соколовського }\end{array}$ & $\begin{array}{l}\text { Таблиці П.С. Мухіна та } \\
\text { Л.І. Сраговіч. } \\
\text { Номограми } \\
\text { Н.К. Звонарьова. } \\
\text { Спосіб А.І. Говядінова - } \\
\text { С.В. Фальковича. } \\
\text { Способи А.М. Сенкова, } \\
\text { І.Д. Молюкова, } \\
\text { Г.Л. Фісенко - } \\
\text { В.Т. Сапожникова } \\
\text { (опуклий схил), } \\
\text { В.Т. Сапожникова - } \\
\text { В.І. Пушкарьова (схил } \\
\text { криволінійний в плані), } \\
\text { Ю.Н. Малюшицького } \\
\text { (багатошаровий схил). }\end{array}$ \\
\hline & & $\begin{array}{l}\text { Графічний спосіб } \\
\text { інтегрування } \\
\text { диференціальних } \\
\text { рівнянь граничного } \\
\text { напруженого стану }\end{array}$ & $\begin{array}{l}\text { Спосіб } \\
\text { С.С. Голушкевіча }\end{array}$ & \\
\hline Б & $\begin{array}{l}\text { Побудова контуру } \\
\text { схилу, уздовж } \\
\text { якого задоволь- } \\
\text { няється рівність } \\
\text { кута нахилу } \\
\text { дотичній куту } \\
\text { опору зрушення }\end{array}$ & \begin{tabular}{|l|} 
Розбивка схилу на \\
горизонтальні шари \\
і визначення сталого \\
кута нахилу кожного \\
шару з урахуванням \\
ваги верхніх порід
\end{tabular} & $\begin{array}{l}\text { Способи } \\
\text { Н.Н. Маслова, } \\
\text { М.Н. Троїцької }\end{array}$ & \\
\hline \multirow[t]{2}{*}{ B } & $\begin{array}{l}\text { Побудова в масиві } \\
\text { поверхні ковзання, } \\
\text { уздовж якої } \\
\text { задовольняється } \\
\text { умова граничної } \\
\text { рівноваги }\end{array}$ & $\begin{array}{l}\text { Плоска поверхня } \\
\text { ковзання }\end{array}$ & $\begin{array}{l}\text { Способи Г. Франсе, } \\
\text { О. Вінклера, } \\
\text { Л.Н. Бернацького, } \\
\text { П.Н. Цимбаревича, } \\
\text { О.Т. Токмурзіна }\end{array}$ & \\
\hline & & $\begin{array}{l}\text { Умови рівноваги } \\
\text { всього схилу (кругло- } \\
\text { циліндрична } \\
\text { поверхня) }\end{array}$ & $\begin{array}{l}\text { Способи } \\
\text { В. Фелленіуса, } \\
\text { Д. Тейлора (коло } \\
\text { тертя) } \\
\end{array}$ & \\
\hline
\end{tabular}


Продовження таблиці

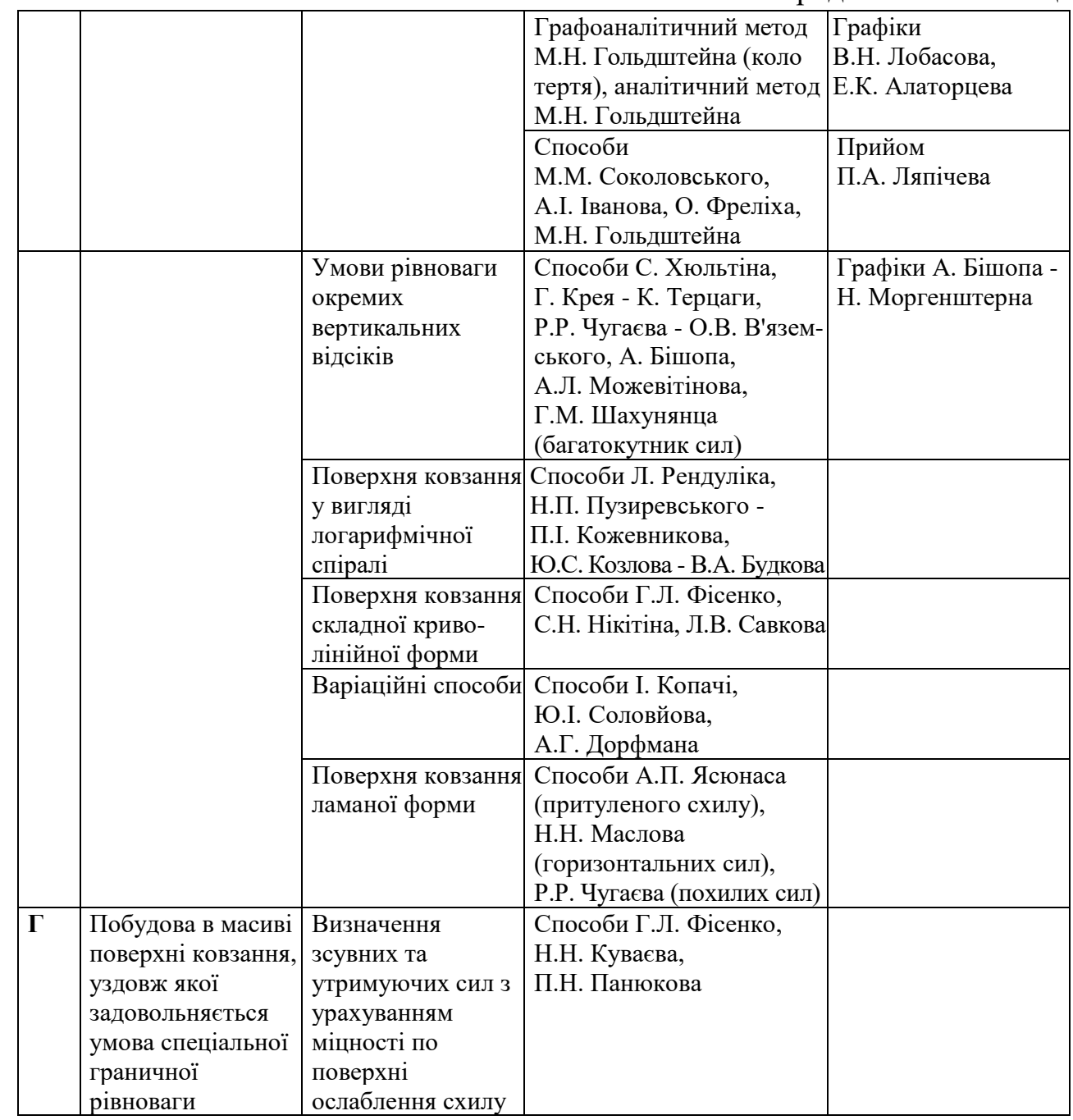

\section{Аналіз методів розрахунку схилів}

До вказаних в таблиці способів для різних поверхонь ковзання схилу необхідно додати способи Янбу, Моргенштерна і Прайса, Спенсера [6]. Ці способи досить схожі і дають близькі результати. Їх принципова різниця полягає в кількості рівнянь рівноваги, які складають для окремих відсіків або для всієї призми зсуву в цілому.

Способи класу Б базуються на припущеннях про те, що у всіх точках кут схилу дорівнює куту опору зрушенню, а також на зовнішній схожості між рівнянням опору сипучих порід зрушенню і рівнянням, що зв'язує висоту схилу 3 його закладенням. Способи даного класу не мають належного теоретичного обгрунтування і не можуть бути розрахунковими.

Способи класу А використовують одне, хоча i досить принципове допущення - в кожній точці призми зсуву виконується умова граничного напруженого стану (закон Кулона). Дані способи виділяють в окремий метод граничного напруженого стану. 
Родоначальником методу $є$ французький вчений Ш.О. Кулон (17361806 рр.), який сформулював в 1773 р. основні положення граничної рівноваги. Шотландський професор У.Д. Ренкін (1820-1872 рр.) в 1857 р. розглянув граничну рівновагу нескінченного масиву, обмеженого нахиленою площиною, а також ввів поняття про поверхні ковзання (див. рисунок).

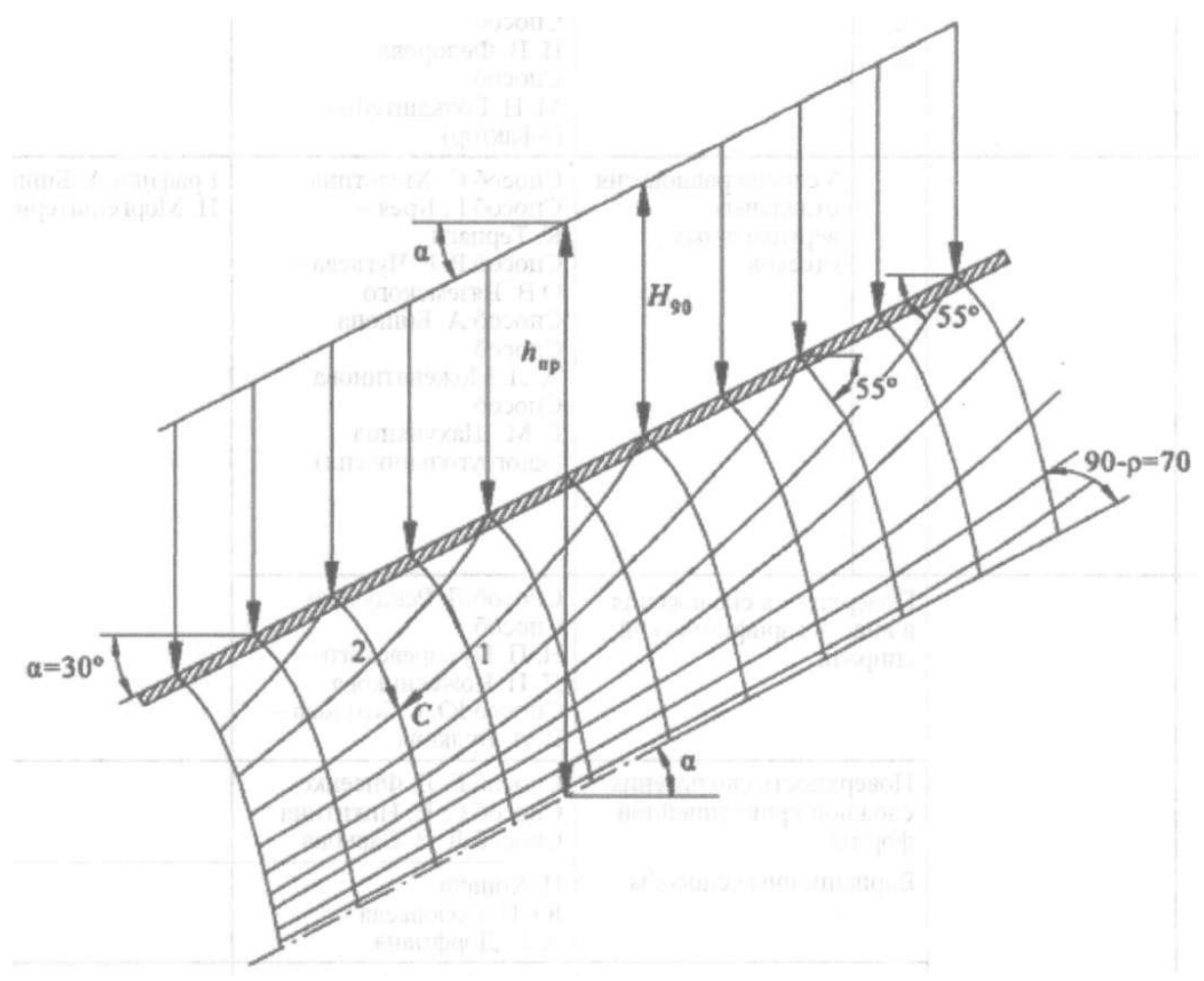

Рисунок - Узагальнена задача Ренкіна

Основою методу, подібно механіці суцільних середовищ (теорії пружності, пластичності і т. п.), є диференціальні рівняння рівноваги у двовимірній постановці:

$$
\begin{aligned}
& \frac{\partial \sigma_{x}}{\partial x}+\frac{\partial \tau_{x y}}{\partial y}=0 \\
& \frac{\partial \sigma_{y}}{\partial y}+\frac{\partial \tau_{x y}}{\partial x}=\gamma
\end{aligned}
$$

де $\gamma$ - об'ємна вага гірських порід; $\sigma_{x}, \sigma_{y}, \tau_{x y}-$ компоненти тензора плоского напруженого стану.

Однак не існувало загального підходу для вирішення завдань граничної рівноваги вагомого сипучого і в'язкого середовища. Лише в 1939 p. В.В. Соколовський [7] розробив такий метод. Ввівши поняття про середню величину наведеної напруги $\sigma=\left(\sigma_{1}+\sigma_{3}\right) / 2+C \operatorname{ctg} \varphi$ та виразивши через неї 
компоненти тензора напружень, В.В. Соколовський отримав так звану основну систему рівнянь граничної рівноваги у симетричному вигляді:

$$
\begin{aligned}
& {\left[\frac{\partial \sigma}{\partial x} \pm 2 \sigma \operatorname{tg} \varphi \frac{\partial \rho}{\partial x} \pm \gamma \operatorname{tg} \varphi\right] \cos (\rho \pm \varepsilon)+} \\
& \quad+\left[\frac{\partial \sigma}{\partial y} \pm 2 \sigma \operatorname{tg} \varphi \frac{\partial \rho}{\partial y} \pm \gamma\right] \sin (\rho \pm \varepsilon)=0
\end{aligned}
$$

де $\rho$ - кут між напрямком найбільшої головної напруги $\sigma_{1}$ i віссю $x$; $\varepsilon=\pi / 4-\varphi / 2$ - кут між напрямком $\sigma_{1}$ і площинами ковзання.

Недоліки методу граничного напруженого стану:

1) неможливість застосування у випадках довільної форми схилу і епюри зовнішнього навантаження, що є наслідком допущення про виконання умови граничного напруженого стану в кожній точці призми зсуву;

2) складність або неможливість застосування у випадках наявності в масиві поверхонь ослаблення (контактів шарів, тріщин і т. п.);

3) трудомісткість і непридатність при адаптації до складних гірничогеологічних умов (сейсмічність, обводненість, об'ємна задача і т. п.).

Способи класу В найбільш різноманітні. Їх відмінність полягає в геометрії використовуваної поверхні ковзання (круглоциліндричних, логарифмічна спіраль і ін.), а також в тому, яким чином судять про стійкість призми зсуву: по рівновазі окремих відсіків (блоків) або для всієї призми зсуву. Дослідники для обгрунтування відсутності недостатньої умови (рівняння) висувають додаткові, найчастіше малообгрунтовані гіпотези про розподіл міжблокових реакцій. Наприклад, деякі з них:

1. реакція між відсіками горизонтальна (Н.М. Герсеванов, Г. Крей, P.Р. Чугаєв - спосіб горизонтальних сил, Н. Янбу);

2. дотична реакція максимальна (Г.М. Шахунянц);

3. реакція відхилена від горизонту на величину половини кута зсуву (Р.Р. Чугаєв - спосіб похилих сил);

4. напрямок реакції паралельний основі подальшого відсіку (Г.Ј. Фісенко алгебраїчне додавання сил);

5. відношення дотичної і нормальної складової - лінійна функція аргументу (спосіб Моргенштерна і Прайса);

6. дотична реакція чисельно дорівнює добутку зчеплення на площу бічної поверхні (Г.М. Шахунянц, 1969);

7. дотична реакція чисельно дорівнює силі тертя при граничній рівновазі по боковій грані відсіку (В.Т. Гузченко й ін.);

8. дотична і нормальна реакції відсіків дорівнюють нулю (Ю.І. Соловйов, К. Терцагі, спосіб алгебраїчного додавання сил).

Зауважимо, що взаємодії між відсіками присутні в будь-якому випадку, інакше напруження в тілі призми зсуву були б нульовими, а це можливо лише в ненавантажених і невагомих середовищах. Однак важливо встановити ступінь їх впливу на стійкість. Так як умова рівноваги визначається лише дією зовнішніх сил (сил, що діють на призму зміщення в цілому), то внутрішні сили (міжблокові реакціі) в критерій стійкості в явному вигляді входити не будуть. Тобто внутрішні сили повинні виражатися у вигляді функції зовнішніх сил. 
Наприкінці відзначимо принципові відмінності між двома основними методами розрахунку (оцінки) стійкості схилів і основні положення кожного 3 них:

1. У методі граничного напруженого стану (клас А) умова граничної рівноваги виконується в кожній точці призми зсуву, в тому числі на поверхні схилу і уздовж поверхні ковзання. Це, зокрема, означає, що напрямок лінії дії найбільшої головної напруги відхилено від майданчиків ковзання кожного із сімейств поверхонь ковзання на кут $\pi / 4-\varphi / 2$. На майданчиках 3 таким орієнтуванням діє максимальна різниця зсувних та утримуючих сил, тобто вони є найбільш небезпечними в даній точці.

2. У методі граничної рівноваги й у всіх його способах (клас В) умова граничної рівноваги (умова пластичності, міцності) виконується тільки уздовж поверхні ковзання, причому орієнтування майданчиків визначається з умови небезпеки (екстремальності) поверхні ковзання в цілому, а не в кожній їі точці. Тобто майданчики зрізу (ковзання) не обов'язково будуть відхилені від напряму першої головної напруги на кут $\pi / 4-\varphi / 2$.

3. Таким чином, незважаючи на деяку схожість методів граничного напруженого стану та граничної рівноваги, їх порівняння необхідно проводити з обережністю.

\section{Висновки}

1. На підставі детального аналізу, проведеного автором, були виділені чотири групи основних припущень, висунутих дослідниками для обгрунтування розрахункової схеми, отримання умов стійкості (рівноваги) призми зсуву і визначення форми і положення найбільш слабкої поверхні ковзання в схилах:

- допущення про виконання умови граничного напруженого стану в кожній точці призми зсуву (метод граничного напруженого стану - способи класу А);

- допущення про розподіл нормальних реакцій уздовж поверхні ковзання (способи монолітного відсіку обвалення, тобто коли розглядають рівновагу призми зсуву цілком);

- припущення щодо співвідношення дотичних і нормальних реакцій по бокових гранях відсіків (реакція горизонтальна, нахилена або гранично відхилена);

• припущення щодо форми і положення (геометрії) потенційної (найбільш слабкої) поверхні ковзання.

2. Всі існуючі методи (способи) в силу статичної невизначеності завдання в будь-якій їх постановці для отримання умови рівноваги призми зсуву використовують ті чи інші припущення. У цьому сенсі жоден з розглянутих способів не є математично коректним. Про ступінь обгрунтованості кожного 3 припущень судити досить складно через відсутність еталонного (коректного) способу розрахунку.

3. Метод граничного напруженого стану найбільш корисний для попередження обвалів схилів, тобто вивчення форми схилів і зовнішнього навантаження, при яких можливе обвалення. Метод граничної рівноваги, у свою чергу, бажано застосовувати для аналізу напруженого стану зсувів. 


\section{СПИСОК ЛІТЕРАТУРИ}

1. Сиренко А.П. Влияние уровня грунтовых вод на устойчивость оползневого склона / А.П. Сиренко // Будівельні конструкції: зб. наук. пр. - К. : ДП НДІБК, 2014. - Вип. 80. C. $210-213$.

2. Stefanyshyn, D. V. (2013). A method of forecasting of indexes of dynamic system that evolves slowly, based on time series analysis. In 4th Int. Conf. on Inductive Modelling (pp. 221-224). Kyiv, Ukraine.

3. Сіренко А.П. Критична відстань між утримуючими елементами для зсувних та зсувонебезпечних схилів Чернівецької області / А.П. Сіренко // Екологічна безпека. 2013. - № 13. - C. 73-76.

4. Trofymchuk O., Kaliukh I., Silchenko K., Polevetskiy V., Berchun V., Kalyukh T. Use accelerogram of real earthquakes in the evaluation of the stress-strain state of landslide slopes in seismically active regions of Ukraine. In: Lollino G. et al. (eds) Engineering Geology for Society and Territory - vol. 2, pp. 1343-1346, Springer, Cham (2015).

5. TXT-tool 2.380-1.1: Monitoring and Early Warning System of the Building Constructions of the Livadia Palace, Ukraine / O. Trofymchuk. I. Kaliukh, O. Klimenkov / In book: Landslide Dynamics: ISDR-ICL Landslide Interactive Teaching Tools. - 2018. - P. 491-508.

6. Хуан Я.Х. Устойчивость земляных откосов / под ред. В.Г. Мельника. М.: Стройиздат. 1988. 240 с.

7. Соколовский В.В. Статика сыпучей среды. М: Наука. 1990. 272 с.

Стаття надійшла до редакиії 20.02.2019 і прийнята до друку після рещензування 07.03.2019

\section{REFERENCES (TRANSLATED AND TRANSLITERATED)}

1. Sirenko, A. P. (2014). Vlijanie urovnja gruntovyh vod na ustojchivost' opolznevogo sklona. Budivel'ni Konstrukcii', (80), 210-213 (in Russian).

2. Stefanyshyn, D. V. (2013). A method of forecasting of indexes of dynamic system that evolves slowly, based on time series analysis. In 4th Int. Conf. on Inductive Modelling (pp. 221-224). Kyiv, Ukraine (in Ukrainian).

3. Sirenko, A. P. (2013). Krytychna vidstan' mizh utrymujuchymy elementamy dlja zsuvnyh ta zsuvonebezpechnyh shyliv Chernivec'koi' oblasti. Ekologichna bezpeka, (13), 73-76 (in Ukrainian).

4. Trofymchuk, O., Kaliukh, I., Silchenko, K., Polevetskiy, V., Berchun, V., \& Kalyukh, T. (2015). Use accelerogram of real earthquakes in the evaluation of the stress-strain state of landslide slopes in seismically active regions of Ukraine. In G. Lollino et al. (eds.), Engineering Geology for Society and Territory (Vol. 2, pp. 1343-1346). Springer, Cham.

5. Trofymchuk, O., Kaliukh, I., \& Klimenkov, O. (2018). TXT-tool 2.380-1.1: Monitoring and Early Warning System of the Building Constructions of the Livadia Palace, Ukraine. In Landslide Dynamics: ISDR-ICL Landslide Interactive Teaching Tools (pp. 491-508).

6. Huan, J. X. (1988). Ustojchivost' zemljanyh otkosov (V. G. Mel'nik, Ed.). Moscow: Strojizdat (in Russian).

7. Sokolovskij, V. V. (1990). Statika sypuchej sredy. Moscow: Nauka (in Russian).

The article was received 20.02.2019 and was accepted after revision 07.03.2019

\section{Сіренко Анатолій Петрович}

кандидат технічних наук, доцент, доцент кафедри динаміки і міцності машин та опору матеріалів Механіко-машинобудівного інституту НТУУ «КПІ ім. Ігоря Сікорського» Адреса робоча: 03056 Україна, м. Київ-56, проспект Перемоги, 37

e-mail: sirenkoap@gmail.com

ORCID ID: 0000-0002-4951-1165 